1.Pamukkale Üniversitesi Fizik Tedavi ve Rehabilitasyon Yüksek Okulu, Denizli

2Empati Özel Eğitim Ve Rehabilitasyon Merkezi, Antalya

3Çă̆la Pınar Özel Eğitim Merkezi, Aydın

4Dumlupınar Üniversitesi, Sağlık Bilimleri Fakültesi, Fizyoterapi Ve Rehabilitasyon Bölümü, Kütahya

Sorumlu yazar yazışma adresi:

Bilge Başakçı Çalık: Pamukkale Üniversitesi Fizik Tedavi ve Rehabilitasyon Yüksekokulu, Kınıklı, Denizli, Türkiye

E-mail: fztbilge@hotmail.com

Geliş tarihi/Received: $\quad$ 23.06.2017

Kabul tarihi/Accepted: 28.11.2019

Yayın hakları Güncel Pediatri'ye aittir.

Güncel Pediatri 2020;18(1):29-40

\author{
DOWN SENDROMLU ÇOCUKLARIN GÜNL ÜK \\ YAŞAMDAKI FONKSIYONEL DÜZEYININ ve \\ YAŞININ ANNELERIN YAŞAM KALITESINE ETKISII
}

\section{The Impact of Functional Independence Level and Age on the Quality of Life of Mothers with Down Syndrome Children}

Bilge Başakçı Çalık ${ }^{1}(0000-0002-7267-7622)$, Sebahat Yaprak Çetin $^{2}(0000-0002-7467-1398)$, Mustafa Can Kılıç ${ }^{3}$, Ferruh Taşpınar ${ }^{4}$ (0000-0002-5084-2949), Ümmühan Baş Aslan'1(0000-0001-6483-503X)

\section{$\ddot{O} Z$}

GİRIŞ̧ ve AMAÇ: Bu çalışma, Down sendromlu çocukların günlük yaşamdaki işlevsel düzeyinin ve yaşının, annelerin yaşam kalitesi üzerine etkisini incelemek amacıyla planlanmıştır.

YÖNTEM ve GEREÇLER: Çalışmaya, yaş ortalaması 7,9 93,5 yıl olan Down sendromlu 37 çocuk alındı. Çocukların işlevsel bağımsılık düzeyi, İşlevsel Bağımsızlık Ölçeği ile, annelerin yaşam kalitesi Kısa Form-36 ile değerlendirildi. İşlevsel Bağımsızlık Ölçeği toplam puanı 36-90 arasında olanlar, gözlem gerektiren Down sendromu grubu $(\mathrm{n}=18)$ ve 91-126 arasında olanlar bağımsız Down sendromu grubu (n=19) olarak iki gruba ayrıld1. İstatistiksel incelemede Mann-Whitney U testi ve Spearman korelasyon testi kullanıldı.

BULGULAR: Gözlem gerektiren Down sendromlu çocukların toplam

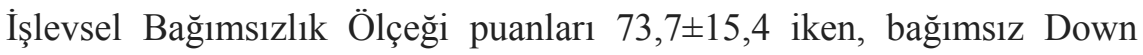

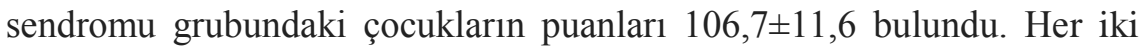
grup açısından ailelerin Kısa Form-36 zihinsel, fiziksel ve toplam

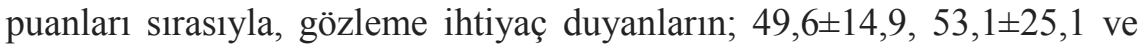
$102,7 \pm 37,4$ iken, bağımsızların; $62,1 \pm 13,9,68,3 \pm 21,6$ ve $130,5 \pm 33,7$ 'dir. Gruplar karşılaştırıldığında Kısa Form-36 Zihinsel ve Kısa Form-36 Toplam puanları bağımsız Down sendromlu çocukların aileleri lehine anlamlı iken $(\mathrm{p}<0,05)$, Kısa Form-36 Fiziksel puanı açısından fark anlamsızdı $(p>0,05)$. Bunun yanı sıra, çocukların yaşları ile annelerin yaşam kalitelerinin tüm alt testleri arasında her iki grupta herhangi bir ilişki bulunmadı $(p>0,05)$. 
TARTIŞMA ve SONUÇ: Çalışmamızın sonucu, Down sendromlu çocukların işlevsel bağımsızlık düzeyine bağlı olarak ailelerin yaşam kalitesinin etkilendiği ve yaşam kalitesindeki etkilenmenin zihinsel açıdan olduğunu düşündürmüştür. Çocuğun yaşı ile annenin yaşam kalitesinin ilişkili olmadığı görülmüştür.

Anahtar Kelimeler: Anne, çocuk, Down sendromu, işlevsel düzey, zihinsel sağlık

\section{ABSTRACT}

INTRODUCTION: This study was investigate the impact of level of functional independence and ages on the quality of life of the mothers in children with Down Syndrome.

MATERIALS and METHODS: Thirtyseven Down syndrome children (7.9 \pm 3.5 years) were included in this study. Functional independent level of children were evaluated by using Functional Independence Measure, mothers quality of life were evaluated by using Sort Form-36. Down syndrome children were classified according their Functional Independence Measure total score into two groups; need observation (36-90 scores) $(n=19)$, and independent (91-126 scores) ( $\mathrm{n}=18)$ groups.

RESULTS: Functional Independence Measure total scores of children in need obsevation group and children in independent group were $73.7 \pm 15.4$, 106.7 \pm 11.6 , respectively. Sort Form -36 Physical, Sort Form -36 Mental and Sort Form -36 Total scores of children in need obsevation group were $53.1 \pm 25.1,49.6 \pm 14.9$ and $102.7 \pm 37.4$ and children in independent group scores were $68.3 \pm 21.6,62.1 \pm 13,9$ and $130.5 \pm 33.7$, respectively. When we compared Sort Form -36 Mental and Sort Form -36 Total scores of the groups were significant in favor of independent group $(\mathrm{p}<0,05)$, but the difference of Sort Form-36 Physical score was insignificant ( $p>0,05)$. In addition, it was found no relationships between the quality of life of mothers and children age in the all groups $(p>0,05)$.

CONCLUSIONS: The results of our study suggested that functional dependence level of Down syndrome children effects on mothers' quality of life and affected domain of quality of life was mental health. It was seen that the age of Down syndrome children did'nt has effect on quality of life of mothers.

Key words: Children, Down syndrome, mothers, functional level, menthal health 


\section{GíRIŞ}

Down Sendromu (DS), ekstra kromozom 21'in bulunduğu durumların ortalama \%93'ünde meydana gelen çoklu konjenital anormallikten oluşan bir bozukluktur (1) .

Down sendromundaki problemleri başlıklar altında toplayacak olursak, motor gelişimde gecikme, duyusal ve motor problemler, algısal bozukluklar, ciddi derecede entelektüel gerilik ve uyumsal davranışlarda bozukluklar şeklinde sıralanabilir(2).

Carr, Down Sendromlu çocuğun zihinsel gelişimine kıyasla motor gelişimi alanında daha az başarılı olduğunu bildirmiştir. Conolly ve Michael, Down Sendromlu çocuklar yürüme, denge, güç, göz-el koordinasyonu, genel kaba ve ince motor becerilerde belirgin derecede düşük bir hıza sahip olduklarını bildirmişlerdir $(3,4)$. Bu nedenle, Down sendromlu çocuklarda meydana gelen motor ve zihinsel yetersizlikler çocukların günlük yaşamda bağımsızlıklarını etkileyebilmektedir.

Tarihsel sürece baktığımızda, engelli çocuğa sahip anne-babaların ve özellikle annelerin yaşamlarının olumsuz etkilendiğini gösterilmiştir(5-7). Olayın kronik olması nedeniyle, ailelerde benlik saygısının değiştiği, kendine güvenin azaldığı, depresyon, sosyal yalıtım, şiddetli emosyonel bozukluklar, evlilik problemlerinde artma, iş bulma ve işe devamlılıkta sorunlar yaşadıkları belirlenmiştir(8-10).

Down sendromlu çocuğun da aile sistemini birçok yoldan etkilemesi olasıdır. Birçok araştırmada Down sendromlu çocukların aile üzerindeki etkileri farklı açılardan ele alınmıştır(11). Bu etkilenimin Down Sendromlu çocuğun bilişsel ve davranışsal fenotipleri ile ilişkisi olabileceği bildirilmiştir. Bunlar; bilgi işleme ve zayıflıktaki güçlüğün özel şekilleri olan sosyal etkileşim, ifade dili, alg1 becerisi, motor beceri ve güdülenmeyi içerir(12-14). Bu durumdaki zayıflıklar temel bakımdan sorumlu olan kişiler olan aile ve bakıcıları etkilerken; diğer taraftan bakım yükünün artması, ailenin bakım rolünde memnuniyetinin azalması ve yaşam içinde kariyer açısından firsatların kaçırılması aileyi olumsuz yönde etkilemektedir(15-17). Down sendromlu çocuklardaki ebeveyn uyumuyla ilgili birçok çalışmada öncelikle stres üzerine odaklanılmıştır. Down sendromlu çocuklarda genel sağlık, eğitim ve gelişimsel geriliklerin birlikte olması nedeniyle ailelerde stres düzeyi daha fazladır.

Literatürde, engelli çocuğu sahip ailelerin ve özellikle annelerin psikolojik açıdan etkilendikleri belirtilmektedir(18-21). Yapılan bir çalışmada Down sendromlu çocuğun davranışlarının ve bakım taleplerinin annelerde zihinsel sağlığı oldukça etkilediği bildirilmiştir.

Çalışmamızın amacı Down sendromlu çocukların günlük yaşamdaki işlevsel düzeylerinin, ailelerin yaşam kalitesi üzerine etkisi olup olmadığını belirlemektir. Bunun yanı sıra çocuğun yaşının annenin yaşam kalitesiyle ilişkisini incelemektedir. 


\section{MATERYAL VE METOT}

Analitik tipte olan bu çalışmaya, özel eğitim ve rehabilitasyon merkezlerinde eğitim alan, yaş aralığı 3-18 yıl ve yaş ortalaması 7,9 3,5 yıl olan Down sendromu tanısı almış 37 çocuğun anneleri alındı. Çalışmaya alınma annelerin gönüllülük esasına ve çocuklarının Down sendrom tanısı almış olmasına dayanırken, iletişim kurulamayan ve gönüllü olmayan anneler çalışmaya alınmadı.

Çalışma, Pamukkale Üniversitesi Girişimsel Olmayan Etik Kurulu'nda değerlendirilerek, etik açıdan uygun bulundu (karar tarihi: 23.06.2013, karar numaras1: 2013/09).

Çalışma kapsamında, çocuk ve annelere ait sosyodemografik bilgiler alındıktan sonra, hazırlanan soru formu ile ailedeki çocuk sayısı, anne ve babanın eğitim düzeyleri, meslekleri, gelir düzeyleri ve medeni durumları sorgulandı. Çocukların günlük yaşamdaki bağımsızlık düzeyi, işlevsel bağımsızlık ölçeği olan WeeFIM, ailelerin yaşam kalitesi ise Kısa Form-36 (KF-36) kullanılarak değerlendirildi.

Işslevsel Bağımsızlık Düzeyi (WeeFIM): Çocuğun günlük yaşam becerilerindeki bağımsızlık performansının derecesi İşlevsel Bağımsızlık Ölçeği WeeFIM ile ölçülmektedir.

İşlevsel Bağımsızlık Ölçeği altı ay ile yedi yaşları arasındaki özürlü çocuklar ile yedi yaşın altındaki bütün çocukların işlevsel bağımsızlığını değerlendirmek ve gelişimlerini izlemek için hem özürlü olanlarda hem de özürlü olmayan çocuklarda geçerli ve güvenilir bir testtir. Bu test gelişim geriliği olan çocuklarda 21 yaşına kadar da uygulanabilmektedir. On sekiz başlık altında çocuğun kendine bakımı, sifinkter kontrolü, transfer etkinlikleri, hareket etkinlikleri, iletişim becerileri ve kognisyon becerilerini sorgulamayı amaçlamaktadır.

İşlevsel Bağımsızlık Ölçeği alt maddelerinin puanlanmasında; yedi: tam bağımsız, altı: modifiye bağımsız, beş: gözlem ile, dört: en az yardım, üç: hafif yardım, iki: en fazla yardım ve bir: tam yardım olmak üzere birden yediye kadar çocuğun işlevleri puanlanır. Birden dörde kadar olan puanlar, çocuğun bir etkinliği tamamlamak için gereken yardım düzeyini gösterir. Beş puan çocuğun beceriyi yapabilmesi için gözlenmesi ya da yetişkinin verdiği ipucunu gösterir. Altı puan çocuğun etkinliği bağımsız olarak tamamlayabildiğini, ancak yardımcı bir araca gereksinim duyduğunu gösterir(22).

İşlevsel Bağımsızlık Ölçeği çocuğun direkt gözlenmesi ile ya da çocuğun genel ve sürekli performansı hakkında bilgi verebilen bir kişi ile görüşülerek ya da bu ikisi birlikte uygulanabilir. Her madde puanlanır. Testten alınabilecek en düşük toplam puan 18 (bütün becerilerde tam bağımlı), en yüksek toplam puan ise $126^{\prime}$ dır (tüm becerilerde tam bağımsız). İşlevsel Bağımsızlık Ölçeği puanına göre Down sendromlu çocukların bağımsızlık düzeylerini gruplandırdığımızda; toplam puanı 36-90 arasında olanlar gözlem gerektiren Down sendromu grubu (n=18) ve 91-126 arasında olanlar bağımsız Down sendrom grubu $(\mathrm{n}=19)$ olarak iki gruba ayrild1.

Sağlıkla İlgili Yaşam Kalitesi (SF-36): Down sendromlu çocuğa sahip annenin genel sağl1k durumunun değerlendirilmesi amacıyla Kısa Form-36 (KF- 36) kullanıldı. Kısa Form-36 anketi yaşam kalitesini değerlendirmede geçerli ve sıklıkla kullanılan bir ölçüttür. Fiziksel işlev, fiziksel rol 
kısıtlaması, emosyonel rol kısıtlaması, vücut ağrısı, sosyal işlev, zihinsel sağlık, canlılık ve genel sağl1k olmak üzere sekiz alt ölçekte 36 soru içerir. Fiziksel bölüm ve zihinsel bölüm olmak üzere iki alt bölümü vardır. Fiziksel bölüm; fiziksel işlez, fiziksel rol, vücut ağrısı ve genel sağlık alt ölçeklerinden; zihinsel bölüm ise, canlılık, sosyal işlev, emosyonel rol ve zihinsel sağlık alt ölçeklerinden oluşur. Kısa Form-36 tıbbi alanda en çok kullanılan yaşam kalitesi ölçeği olup Türkçe geçerlilik çalışması Koçyiğit ve ark24 tarafından yapılmıştır.

Istatistiksel Analiz: Elde edilen veriler SPSS (Statistical Package for the Social Sciences versiyon 16, Chicago, IL, USA) 16 paket programı ile değerlendirildi. Çalışmanın sayısal değişkenleri ortalama \pm standart sapma $(\operatorname{Or} t \pm S S)$, sayı ve yüzde olarak (n, \%) gösterildi. İki grubun sayısal değişkenler açısından karşılaştırılmasında nonparametrik test olan Mann-Whitney U testi kullanıldı. Down sendromlu çocuğun yaşının annenin yaşam kalitesine etkisini incelemek amacıyla Spearman korelasyon analizi kullanıldı. Tüm istatistiklerde p anlamlılık değeri 0,05 olarak alındı.

\section{BULGULAR}

Down sendromlu çocukların tanımlayıcı özelliklerinin dağılımı ile ilgili bilgiler Tablo 1'de verilmiştir.

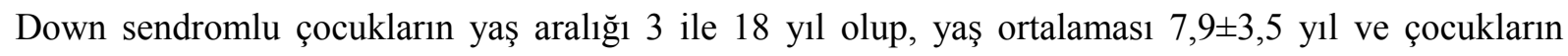
\%54,1'nin $(\mathrm{n}=20)$ cinsiyetinin kız olduğu belirlenmiştir. Çalışmaya alınan anne-babalara ait demografik özellikler, eğitim ve meslek durumları, ailenin toplam aylık gelir dağılımı da Tablo 1'de yer almaktadır.

İşlevsel Bağımsızlık Ölçeği Wee-FIM toplam puanlarına göre; gözlem gerektiren Down sendromlu

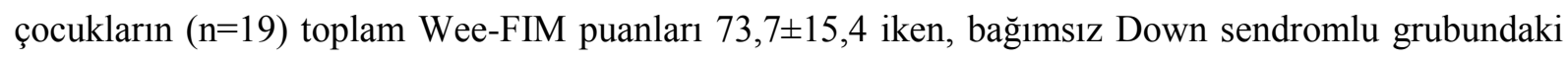
çocukların ( $\mathrm{n}=18$ ) Wee-FIM puanları 106,7 $\pm 11,6$ bulundu. Grupların Wee-FIM alt testlerinin tamamı ve toplam puan gruplar arasında karşılaştırıldığında bağımsız Down sendromlu çocuklar lehine anlamlı bulundu $(\mathrm{p}<0,05)$ (Tablo 2).

Her iki gruptaki annelerin KF-36 zihinsel, fiziksel ve toplam puanları sırasıyla, gözleme ihtiyaç duyanların; $49,6 \pm 14,9,53,1 \pm 25,1$ ve $102,7 \pm 37,4$ iken; bağımsızların $62,1 \pm 13,9,68,3 \pm 21,6$ ve $130,5 \pm 33,7$ 'dir (Tablo 2).

Kısa Form-36 Zihinsel ( $\mathrm{p}=0,018)$ ve KF-36 Toplam ( $\mathrm{p}=0,036)$ puanları bağımsız Down sendromlu çocukların anneleri lehine anlamlı iken, KF-36 Fiziksel puanı açısından fark anlamsızdı $(p=0,062)$ (Tablo 2). 
Tablo 1. Down sendromlu çocukların sosyodemografik özellikleri

\begin{tabular}{ll}
\hline & Ort \pm SS \\
\hline Yaş (yıl) & $7,9 \pm 3,5^{\mathrm{a}}$ \\
& \\
Cinsiyet & \\
Kiz & $20(54,1)^{\mathrm{b}}$ \\
Erkek & $17(45,9)^{\mathrm{b}}$ \\
& $40,1 \pm 6,1^{\mathrm{a}}$
\end{tabular}

Annenin yaşı (yıl)

Ailenin toplam gelir düzeyi

0-1 499 TL (düşük)

$14(37,8)^{\mathrm{b}}$

1500-2 500 TL (orta)

$22(59,5)^{\mathrm{b}}$

2500 TL ve üzeri (yüksek)

$1(2,7)^{\mathrm{b}}$

Anne eğitim durumu

İlkokul

$17(45,9)^{\mathrm{b}}$

Ortaokul

$9(24,3)^{\mathrm{b}}$

Lise

$11(29,7)^{\mathrm{b}}$

Baba eğitim durumu

İlkokul

$9(24,3)^{\mathrm{b}}$

Ortaokul

$6(16,2)^{b}$

Lise

$19(51,4)^{\mathrm{b}}$

Üniversite

$3(8,1)^{\mathrm{b}}$

Anne iş durumu

Çalışıyor

$2(5,4)^{\mathrm{b}}$

Çalışmıyor

$34(91,9)^{\mathrm{b}}$

Emekli

$1(2,7)^{\mathrm{b}}$

Baba iş durumu

Çalışıyor

$31(83,8)^{\mathrm{b}}$

Çalışmıyor

$5(13,5)^{\mathrm{b}}$

Emekli

$1(2,7)^{\mathrm{b}}$

Anne baba birlikteliği

Evli beraber yaşıyor $37(100)^{\mathrm{b}}$

${ }^{a}$ Ort \pm SS: Ortalama \pm Standart sapma, ${ }^{b} n(\%)$ 
Tablo 2. Down sendromlu çocukların Wee-FIM ve annelerin KF-36 sonuçları

\begin{tabular}{|c|c|c|c|c|c|}
\hline \multirow{2}{*}{$\begin{array}{c}\text { Down } \\
\text { sendromlu } \\
\text { çocuklar }\end{array}$} & \multicolumn{2}{|c|}{$\begin{array}{l}\text { Gözlem gerektiren grup } \\
\qquad(n=19)\end{array}$} & \multicolumn{2}{|c|}{ Bağımsız grup $(n=18)$} & \multirow[b]{2}{*}{$\mathbf{p}^{*}$} \\
\hline & $\begin{array}{l}\text { Endüşük-en } \\
\text { yüksekMak }\end{array}$ & Ort $\pm \mathrm{SS}$ & $\begin{array}{l}\text { En düşük-en } \\
\text { yüksek }\end{array}$ & Ort \pm SS & \\
\hline \multicolumn{6}{|l|}{ Wee-FIM } \\
\hline $\begin{array}{l}\text { Kendine } \\
\text { bakım }\end{array}$ & $7-33$ & $20,8 \pm 7,8$ & $23-44$ & $35,7 \pm 5,4$ & $0,0011^{*}$ \\
\hline Sfinkter & $2-14$ & $7,7 \pm 5,2$ & $10-14$ & $13,5 \pm 1,0$ & $0,0011^{*}$ \\
\hline Mobilite & $7-21$ & $18,8 \pm 3,6$ & $18-21$ & $20,8 \pm 0,7$ & $0,011^{*}$ \\
\hline Lokomasyon & $7-14$ & $12,6 \pm 2,0$ & $12-14$ & $13,8 \pm 0,5$ & $0,008^{*}$ \\
\hline İletişim & $2-13$ & $6,4 \pm 2,9$ & $4-14$ & $10,1 \pm 2,6$ & $0,001 *$ \\
\hline Sosyal iletişim & $3-18$ & $7,6 \pm 4,4$ & $5-19$ & $13,1 \pm 4,9$ & $0,003^{*}$ \\
\hline Toplam puan & $38-90$ & $73,7 \pm 15,4$ & $91-122$ & $106,7 \pm 11,6$ & $0,001^{*}$ \\
\hline \multicolumn{6}{|l|}{ KF-36 } \\
\hline Fiziksel & $17,50-92$ & $53,1 \pm 25,1$ & $24-94$ & $68,3 \pm 21,6$ & 0,062 \\
\hline Zihinsel & $10,50-71,75$ & $49,6 \pm 14,9$ & $34,25-86,25$ & $62,1 \pm 13,9$ & $0,018^{*}$ \\
\hline Toplam & $30,50-163,75$ & $102,7 \pm 37,4$ & $58,25-167,75$ & $130,5 \pm 33,7$ & 0,036 * \\
\hline
\end{tabular}

* Mann Whitney U testi

Gözlem gerektiren ve bağımsız grup Down sendromlu çocukların yaşları ile annenin KF-36 puanları arasında ilişki saptanmadı ( $>>0,05)$ (Tablo 3).

Tablo 3. Down sendromlu çocukların yaşları ile annelerin yaşam kalitesi arasındaki ilişki

\begin{tabular}{ccccc}
\hline $\begin{array}{c}\text { Annelerin KF- } \\
36 \text { puanları }\end{array}$ & \multicolumn{2}{c}{$\begin{array}{c}\text { Gözlem gerektiren grup } \\
(\mathbf{n = 1 9 )}\end{array}$} & \multicolumn{2}{c}{ Bağımsız grup (n=18) } \\
\cline { 2 - 5 } & $\mathrm{r}$ & $\mathrm{p}^{*}$ & $\mathrm{r}$ & $\mathrm{p}^{*}$ \\
Fiziksel &,- 121 & $0,621^{*}$ &,- 154 & 0,542 \\
Zihinsel &,- 139 & $0,571^{*}$ &,- 088 & 0,727 \\
Toplam &,- 101 & $0,681^{*}$ &,- 140 & 0,578 \\
\hline
\end{tabular}




\section{TARTISMA}

Down sendromlu çocukların işlevsel düzeylerinin, annenin yaşam kalitesi üzerinde etkisini incelemek amacıyla yapılan bu çalışmada, çocuğun bağımsızlık düzeyindeki azalmanın annenin yaşam kalitesini etkilediği ve bu etkilenimin zihinsel açıdan olduğu belirlendi. Bunun yanı sıra Down sendromlu çocukların yaş artışının annelerin yaşam kalitesini olumsuz yönde etkilemediği görüldü.

Engelli ya da kronik hastalığa sahip çocukları olan ailelerin psikolojik açıdan yüksek stres yaşadıkları diğer çalışmalarda benzer sonuçlarla ifade edilmektedir (26-27).

Eisenhower ve ark. üç yaşındaki davranış problemi olan Down sendromlu çocuklar ile normal çocuğu karşılaştırmışlar ve iki yıl izlem sonunda Down sendromlu çocukta davranış problemlerinin arttığı ve bu durumun ailede stres oluşturduğunu bildirmişlerdir (28).

Bourke ve ark. Down sendromlu çocukların ailelerinin çalışmamızın sonuçlarına benzer olarak zihinsel açıdan daha fazla etkilendiklerini, bu etkilenimin çocuğun davranışları ve bakım gereksinimiyle ilişkili olduğunu belirtmişlerdir ve daha uyumsuz davranışı olan Down sendromlu çocuğa sahip annelerde stres seviyesinin daha fazla olduğu bildirmişlerdir (29). Ayrıca, aileler çocuklarının alışveriş yapma ve toplu taşıma araçlarını kullanma gibi günlük hayattaki işlevsel bağımsızlık düzeylerinin çocuğun var olan güncel sağlık problemlerinden daha fazla kendilerini etkilediğini ifade etmişlerdir. Bizim çalışmamızda da bağımlı gruptaki çocukların kendine bakım, anlama becerileri ve sosyal iletişim aktivitelerinde belirgin düzeyde düşük puan aldıklarını ve bu grubun annelerinin zihinsel açıdan daha kötü oldukları görülmüştür.

Serebral paralizili çocuğa sahip ailelerde çocuğun bağımsızlık seviyesi artıkça ailelerin iş yükünün azaldığını ve fiziksel sağlıklarının daha iyi olduğu gösterilmiştir(30). Ancak buna karşıt olarak çocuğun işlevsel düzeyi ile ailelerin fiziksel sağlığı arasında ilişki bulamayan çalışmalarda bulunmaktadır(31-34). Bizim çalışmamızda da çocuğun işlevsel düzeyi ile ailelerin zihinsel açıdan etkilendiği görülse de, fiziksel açıdan anlamlı düzeyde bir etkilenmenin olmadığı görülmüştür. Ayrıca bazı çalışmalarda da Down sendromlu çocuğa sahip ailelerin otizm, zihinsel engel ve etiyolojisi bilinmeyen özür gruplarına sahip ailelerden daha avantajlı olduğu da bildirilmektedir.

Hauser-Cram ve ark. Down sendromlu çocuğa sahip ailelerin ailesel yükünü araştıran longitüdinal bir araştırmada üç yaşından 10 yaşına kadar yedi yıl boyunca çocuklar izlenmiş ve ebeveynlerin ailesel yükünün çocuğun yaşıyla birlikte arttığı ve bu artışın bilinmeyen kökenli gelişimsel geriliği olan çocukların annelerinden ya da motor bozukluğu olan çocukların annelerinden daha fazla olduğu bulunmuştur(35).

Farklı etiyolojilere sahip zihinsel engelli çocukların ebeveynler üzerindeki stres düzeylerinin araştırıldığ diğer longitüdinal bir çalışmada da çocuklar 12 aylık olduğunda Down sendromlu çocuğa sahip ailelerin stres düzeyleri, diğer özüre sahip ailelerden daha düşük düzeyde bulunurken; çocuklar 45 aylık olduğunda yapılan değerlendirmede gruplar arasında ailelerin stres düzeyleri arasında fark 
olmadığ1 görülmüştür (36). Down Sendromlu çocukların annelerin stres düzeyindeki artışın çocuğun yaşının artışıyla motor gelişiminin yetersizliğinden kaynaklanabileceğini bildirmişlerdir. Bizim çalışmamızda ise çocuğun yaşı ile annenin yaşam kalitesinin ilişkili olmadığı görülmüştür. Çocukların yaşlarının artması, annelerin yaşam kalitesine olumsuz bir etki yaratmamıştır. Hauser-Cram ve ark. ile Most ve ark. farklı sonuç bulmamızın nedeninin çalışmamızın örneklem büyüklüğünden ve diğer çalışmalardaki yaş aralıklarının bizim çalışmamızdan daha düşük olmasından kaynaklanabileceğini düşünmekteyiz.

$\mathrm{Bu}$ çalışmanın en önemli kısıtlılığı, çocukların sadece işlevsel bağımsızlık düzeylerini değerlendirilmesi, ailelerin zihinsel sağlığını etkileyebilecek diğer etmenlerin incelenmemesidir ve ileriki çalışmalarda bu etmenlerin incelenmesi gerektiğine inanmaktayız.

Bizim sonuçlarımıza göre bağımsızlık düzeyi düşük olan Down sendromlu çocuğa sahip annelerin zihinsel sağlıklarının kötü olduğu gösterilmiştir. Elde ettiğimiz bu sonuç Down sendromlu çocukların annelerin desteğe ihtiyaçlarının olduğunu göstermektedir.

Pourmohamadreza-Tajrıshı ve ark. Down sendromlu çocukların annelerinde psiko-sosyal problemleri gidermeye yönelik uyguladıkları problem odaklı eğitim stratejisi ile annelerin çocuklarını anlama yöntemlerini geliştirerek kendi zihinsel sağlıklarının artabileceğini bildirmişlerdir(37). Douma ve ark. zihinsel engelli gençlerin ailelerinin \%88,2'sinin çeşitli desteğe ihtiyaç duyduklarını ve bunların sıklıkla karşılanmadığını belirtmişlerdir (38). King ve ark. davranış problemi olan çocukların belirlenmesinde aile merkezli servislerin yararlı olacağını belirtmişlerdir (31). Raina ve ark. aynı şekilde, engelli çocuğa sahip ailelerin sağlığı için çocuğun davranış problemlerinin yanı sıra işlevselliğinin de aileleri nasıl etkilediğinin aile merkezli olarak değerlendirilmesi gerektiğini vurgulamışlardır (30). Engellilik toplum içerisinde tipik bir yük olarak görülmektedir, Down sendromu olan bir çocuk ve ebeveynleri hakkında toplumun genelinin oldukça olumsuz görüşe sahip olması aile üzerindeki yükü daha da artırmaktadır. Down sendromlu çocukların problemlerine yönelik yapılacak müdahalenin çocuğun durumunu olumlu yönde değiştirerek, annelerin sağlığını da etkileyeceği düşünülmektedir. Mac Conachie ve Diggle erken müdahale çalışmalarının annelerin üzerinde olumlu etkisini vurgulamıştır(39).

Sonuç ve Öneriler: Tüm bu sonuçlar doğrultusunda Down sendromlu çocuğu sahip annelerin zihinsel sağlığının çocuğun işlevsel bağımsızlık düzeyi ile ilişkili olduğu ancak çocuğun yaşından etkilenmediğini görmekteyiz. İleriki çalışmalarda, annelerin zihinsel sağlığını etkileyebilecek diğer durumların irdelenmesi ve annelerin zihinsel sağlığının desteklenmesi için uygun yaklaşımların yapılmasını önermekteyiz.

Çıkar çatışması: yoktur

Finansman desteği: yoktur 


\section{KAYNAKLAR}

1.Lauteslager PEM. Down Sendromlu çocuklarda motor gelişim ve müdahalesi, Baskı Evi Matbaa, Hollanda, 2004.

2.Leonard S, Msall M, Bower C, Tremont M, Leonard H. Functional status of school-aged children with Down syndrome. J Paediatr Child Health. 2002; 38: 160-5.

3.Carr J. Mental and motor development in young mongol children. J Ment Defic Res. 1970; 14: 20520.

4.Connolly BH, Michael BT. Performance of retarded children, with and without Down's syndrome, on the Bruininks Oseretsky test of motor proficiency. Phys Ther. 1986; 66: 344-8.

5.Damrosch S, Perry L. Self-reported adjustment, chronic sorrow, and coping of parents of children with Down syndrome. Nurs Res. 1989; 38: 25-30.

6.Olshansky S. Chronic sorrow: A response to having a mentally defective child. Soc Casework. 1962; 43: 190-3.

7.Wikler L, Wasow M, Hatfied E. Chronic sorrow revisited: Parents vs. professional depiction of the adjustment of parents of mentally retarded children. Am J Orthopsychiat. 1981; 51: 63-70.

8.Olsson MB, Hwang PC. Depression in mothers and fathers of children with intellectual disability. J Intellect Disabil Res. 2001; 45: 535-43.

9.Spangenberg J, Theron J. Stress and coping in parents of children with Down syndrome. Stud Psychol. 2000; 43: 41- 8.

10.Seltzer MM, Greenberg JS, Floyd FJ, Pettee Y, Hong J. Life course impacts of parenting a child with a disability. Am J Ment Retard. 2001; 106: 265- 86.

11.Hodapp RM. Families of persons with Down syndrome: New perspectives, findings, and research and service needs. Ment Retard Dev Disabil Res Rev. 2007; 13: 279-87.

12.Fidler DJ. The emergence of a syndrome-specific personality profile in young children with Down syndrome. Downs Syndr Res Pract. 2006; 10(2): 53-60. doi: 10.3104/reprints.305.

13.Fidler DJ, Hepburn S, Rogers S. Early learning and adaptive behaviour in toddlers with Down syndrome: Evidence of an emerging behavioural phenotype. Downs Syndr Res Pract. 2006; 9(3): 37 44. 
14.Silverman W. Down syndrome: cognitive phenotype. Ment Retard Dev Disabil Res Rev. 2007; 13: $228-36$.

15.Scorgie K, Sobsey D. Transformational outcomes associated with parenting children who have disabilities. Ment Retard. 2000; 38(3): 195-206.

16.Van Riper M. A change of plans: the birth of a child with Down syndrome doesn't have to be a negative experience. Am J Nurs. 2003; 103: 71-4.

17.Van Riper M. Families of children with Down syndrome: Responding to "a change of plans" with resilience. J Pediatr Nurs. 2007; 22: 116-28.

18.Baker BL, McIntyre LL, Blacher J, et al. Pre-school children with and without developmental delay: Behavior problems and parenting stress over time. J Intellect Disabil Res. 2003; 47: 217- 30.

19.Hedov G, Anneren T, Wikblad K. Swedish parents of children with Down's syndrome. Scand J Caring Sci. 2002; 16: 424- 30.

20.Lam L, Mackenzie A. Coping with a child with Down syndrome: The experiences of mothers in Hong Kong. Qual Health Res. 2002; 12: 223- 37.

21.Olsson MB, Hwang PC. Influence of macrostructure of society on the life situation of families with a child with intellectual disability: Sweden as an example. J Intellect Disabil Res. 2003; 47: 32841.

22.Msall ME, DiGaudio K, Duffy LC, LaForest S, Braun S, Granger CV. WeeFIM: normative sample of an instrument for tracking functional independence in children. Clin Pediatr. 1994; 33: 431-8.

23.Wong V, Wong S, Chan K, Wong W. Functional Independence Measure (WeeFIM) for Chinese children: Hong Kong cohort. Pediatrics 2002; 109 (2): E36

24.Koçyiğit H, Aydemir Ö, Fişek G, Memiş A. Kısa Form-36 (KF-36)' nın Türkçe versiyonunun Güvenilirliği. İlaç ve Tedavi Dergisi. 1998; 12: 102-6.

25.Tabachnick B, Fidell L. Computer-Assisted research Design and Analysis. Boston: Allyn and Bacon; 2001.

26.Esdaile SA, Greenwood KM. A comparison of mothers' and fathers' experience of parenting stress and attributions for parent child interaction outcomes. Occup Ther Int. 2003; 10: 115-26.

27.Glidden LM, Schoolcraft SA. Depression: its trajectory and correlates in mothers rearing children with intellectual disability. J Intellect Disabil Res. 2003; 47: 250-63. 
28.Eisenhower AS, Baker BL, Blacher J. Preschool children with intellectual disability: Syndrome specificity, behavior problems, and maternal well-being. J Intellect Disabil Res. 2005; 49: 657-71.

29.Bourke J, Ricciardo B, Bebbington A, Aiberti K, Jacoby P, Dyke P, et al. Physical and Mental Health in Mothers of Children with Down Syndrome. J Pediatr. 2008; 153: 320-6. 